\title{
Why Do Irritable Bowel Syndrome Women Often Have Nausea Symptom?
}

\author{
Full-Young Chang \\ Division of Gastroenterology, Taipei Veterans General Hospital and National Yang-Ming University School of Medicine, Taipei, Taiwan
}

Article: Gender role in irritable bowel syndrome: a comparison of irritable bowel syndrome module (ROME III) between male and female patients Anbardan SJ, Daryani NE, Fereshtehnejad SM, Taba Taba Vakili S, Keramati MR, Ajdarkosh H (J Neurogastroenterol Motil 2012;18:70-77)

Apart from the well-known reproduction, sexual differentiation in humans leads to the distinct behavioral manifestations. For example, the central pain modulation after noxious injury is gender-determined since severe pain is often experienced and reported by the female subjects. ${ }^{1}$ With regard to the gastrointestinal (GI) tract, gender also plays the distinct role in terms of motility, visceral sensation, pharmacokinetics, pharmacodynamics and drug toxicity etc. ${ }^{2-5}$ Accordingly, various functional GI disorders including irritable bowel syndrome (IBS), functional bloating, constipation, functional abdominal pain and pelvic floor dysfunction etc are more prevalent in women than men owing to these gender-determined obvious behaviors. ${ }^{5}$ Among the gender effect on IBS manifestations, it is already confirmed that the IBS prevalence reported in Western countries is higher in women compared to men, whereas this characteristic has not always been confirmed in Asia studies. ${ }^{5-7}$ It is of interest why women would more easily report IBS symptoms meeting IBS diagnostic criteria. Probably, women usually suffer the higher levels of GI and non-GI sensory symptoms despite of similar levels of IBS severity, and their central visceral sensory processing shows a great- er activation to anticipate these stimuli. ${ }^{1,8,9}$ In addition, the gender difference also impacts on the distinct colonic and extra-colonic symptoms, health-seeking behaviors, somatic complaints, sleep quality as well as psychological behaviors including somatization, depression and anxiety etc in IBS subjects. ${ }^{10,11}$ All these female behavioral characteristics would then confound the IBS manifestations and lead to meet diagnostic criteria more easily. These gender-determined differences also influence the effective IBS therapy using various measures. It is why there is a greater clinical response to serotonergic agents observed in IBS women compared to men. ${ }^{5,12}$

Based on the questionnaire distributed to the IBS patients seen in an Iranian outpatient clinic with the obtained results published in this issue, Anbardan et $\mathrm{al}^{13}$ mainly pointed out that IBS women diagnosed by Rome III criteria were usually constipation-predominant, whereas the male counterparts were diarrhea-predominant. In fact, the expected proportional difference did not statistically exist. It is likely due to the small-sample size of the study and the cultural background in terms of economic state, education, medical seeking behavior and convenience etc,

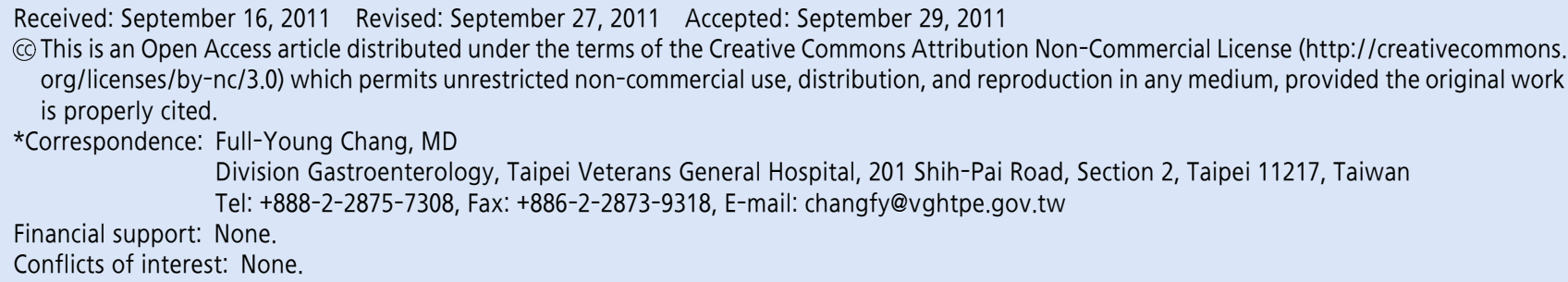


which may account for their unexpected observation. However, their particular addressing on the stool form scale of IBS men who obviously passed looser, mushy and watery stool appears to confirm this characteristic IBS subtype manifestation. Actually, this gender difference on IBS subtypes is not new in Asia, and a selected population study in Taiwan already confirmed it. ${ }^{10}$ The authors have made a contribution in this issue by confirming the gender effect using the new Rome III criteria. Unfortunately, they did not discuss in detail why these IBS women often expressed the constipated bowel symptom. With regard to this putative mechanism, the role of sexual hormones on GI motility and secretion should not be neglected. ${ }^{3}$ For instance, genistein (a natural phytoestrogen) administration to the male mice resulted in more chloride ion secretion probably resulting in enhanced water secretion. ${ }^{14}$ However, it remains uncertain whether this gender-determined secretory mechanism is definitely responsible for male IBS patients to exhibit diarrhea-predominant symptom. Alternatively, the slower GI motility of females may result in constipation symptom, eg, the radio-opaque marker based GI transit study for the constipated females pointed out that a Bristol stool form value $<3$ could predict delayed whole-gut transit with a sensitivity of $85 \%$ and specificity of $82 \%$ and the delayed colonic transit with a sensitivity of $82 \%$ and specificity of $83 \% .^{15}$ Besides, menstrual and postmenopausal women may have different GI physiology and pathophysiology. Accordingly, both postmenopausal and menstruating women reported more somatic symptoms than men with IBS. This effect was also obviously observed among the postmenopausal women. ${ }^{16}$ Since the authors had tried looking for the gender effect on IBS manifestations, the influence of gestation age on female subjects should have been considered during their initial study design. Further addressing on this issue is needed to answer the drawback of this gender study.

The authors never tried to study the associated functional dyspepsia (FD) or reflux disease among the enrolled IBS patients, hence it is unknown why the authors particularly addressed the role of some upper GI symptoms in terms of reflux, nausea, vomiting, anorexia and heartburn among these patients. Surprisingly, the authors indicated that Iranian IBS females almost had 2.7-fold chance to report nausea symptom (49\% vs $18.2 \%, P<0.001)$. However, they did not address on why the female IBS patients were more likely to report nausea. In fact, nausea belonged to one of the upper GI dyspeptic symptoms which was not an IBS component no matter what definition was employed. Interestingly, bloating, nausea and early satiety were frequently reported among the dyspeptic women, whereas food regurgitation and heartburn were commonly observed in male subjects. ${ }^{17}$ The situation of IBS patients to overlap with FD is not uncommon in accordance with various Rome criteria. ${ }^{6}$ Accordingly, it is also unknown whether these Iranian women with nausea were exactly associated with dyspepsia or FD together. Regarding to gender impact on FD, females also have more chance to develop FD. ${ }^{18}$ In addition, delayed gastric emptying (GE) in dyspeptic patients is often characterized by female sex, presence of relevant and severe postprandial fullness, nausea and vomiting etc. ${ }^{19}$ It probably means that nausea in dyspepsia is somewhat linked with poor GE, particularly among the female subjects. Since the female subjects may have a delayed GE, it is reasonable to suggest that some IBS women with delayed GE may easily express nausea symptom as well as the results published in this issue. ${ }^{3,13}$

In conclusion, the authors confirmed again that Asian IBS women are likely constipation-predominant, whereas male patients are diarrhea-predominant according to the recorded stool form scale. The additional finding of commonly existed upper GI nausea symptom among IBS women represents the effect of well-known delayed GE already reported in other gender studies.

\section{References}

1. Popescu A, LeResche L, Truelove EL, Drangsholt MT. Gender differences in pain modulation by diffuse noxious inhibitory controls: a systematic review. Pain 2010;150:309-318.

2. Chen TS, Doong ML, Chang FY, Lee SD, Wang PS. Effects of sex steroid hormones on gastric emptying and gastrointestinal transit in rats. Am J Physiol 1995;268(1 Pt 1):G171-G176.

3. Sadik R, Abrahamsson H, Stotzer PO. Gender differences in gut transit shown with a newly developed radiological procedure. Scand J Gastroenterol 2003;38:36-42.

4. Freire AC, Basit AW, Choudhary R, Piong CW, Merchant HA. Does sex matter? The influence of gender on gastrointestinal physiology and drug delivery. Int J Pharm 2011;415:15-28.

5. Chang L, Toner BB, Fukudo S, et al. Gender, age, society, culture, and the patient's perspective in the functional gastrointestinal disorders. Gastroenterology 2006;130:1435-1446.

6. Gwee KA, Bak YT, Ghoshal UC, et al. Asian consensus on irritable bowel syndrome. J Gastroenterol Hepatol 2010;25:1189-1205.

7. Chang FY, Lu CL, Chen TS. The current prevalence of irritable bowel syndrome in Asia. J Neurogastroenterol Motil 2010;16:389400.

8. Lee OY, Mayer EA, Schmulson M, Chang L, Naliboff B. Gender-related differences in IBS symptoms. Am J Gastroenterol 2001;96:2184-2193.

9. Naliboff BD, Berman S, Chang L, et al. Sex-related differences in IBS patients: central processing of visceral stimuli. Gastroenterology 2003;124:1738-1747. 
10. Lu CL, Chang FY, Lang HC, Chen CY, Luo JC, Lee SD. Gender difference on the symptoms, health-seeking behaviour, social impact and sleep quality in irritable bowel syndrome: a Rome II-based survey in an apparent healthy adult Chinese population in Taiwan. Aliment Pharmacol Ther 2005;21:1497-1505.

11. Chang L, Heitkemper MM. Gender differences in irritable bowel syndrome. Gastroenterology 2002;123:1686-1701.

12. Cremonini F, Delgado-Aros S, Camilleri M. Efficacy of alosetron in irritable bowel syndrome: a meta-analysis of randomized controlled trials. Neurogastroenterol Motil 2003;15:79-86.

13. Anbardan SJ, Daryani NE, Fereshtehnejad SM, Taba Taba Vakili S, Keramati MR, Ajdarkosh H. Gender role in irritable bowel syndrome: a comparison of irritable bowel syndrome module (ROME III) between male and female patients. J Neurogastroenterol Motil 2012;18:70-77.

14. Al-Nakkash L, Batia L, Bhakta M, et al. Stimulation of murine intestinal secretion by daily genistein injections: gender-dependent differences. Cell Physiol Biochem 2011;28:239-250.
15. Saad RJ, Rao SS, Koch KL, et al. Do stool form and frequency correlate with whole-gut and colonic transit? Results from a multicenter study in constipated individuals and healthy controls. Am J Gastroenterol 2010;105:403-411.

16. Cain KC, Jarrett ME, Burr RL, Rosen S, Hertig VL, Heitkemper MM. Gender differences in gastrointestinal, psychological, and somatic symptoms in irritable bowel syndrome. Dig Dis Sci 2009;54: 1542-1549.

17. Westbrook JI, Talley NJ, Westbrook MT. Gender differences in the symptoms and physical and mental well-being of dyspeptics: a population based study. Qual Life Res 2002;11:283-291.

18. Olafsdottir LB, Gudjonsson H, Jonsdottir HH, Thjodleifsson B. Natural history of functional dyspepsia: a 10-year population-based study. Digestion 2010;81:53-61.

19. Stanghellini V, Tosetti C, Paternico A, et al. Risk indicators of delayed gastric emptying of solids in patients with functional dyspepsia. Gastroenterology 1996;110:1036-1042. 